\title{
A study of the parameters that influence orthosurgical treatments
}

\author{
I. Dallel ${ }^{1}$, S. Tobji ${ }^{2}$, A. Ben Amor ${ }^{2}$
}

Associate Professor in Dentofacial Orthodontics

2 ODF Professor, Oral Health and Orofacial Rehabilitation Research Laboratory LR12ES11, Monastir University, Monastir Dentofacial Orthopedics Department, Tunisia

ABSTRACT

Introduction: In daily practice, the orthodontist may have some difficulties with their therapeutic decision to choose a treatment with or without orthognathic surgery, especially for borderline cases. The objective of this study is to determine the outcome of orthosurgical treatment.

Patients and Methods: We undertook a retrospective analytical study of 175 randomly selected cases. The data for this study were obtained from lateral cephalograms radiographs, panoramic radiographs, both intraoral and extraoral photographs, and case sheet, and clinical examination.

Results: According to the multivariate data analysis and the results of studied factors in determining the need for orthosurgical treatment were: the chin position, the FMA angle and the ratio of the lips based on this formula: $1.167+0.288 \times$ the position of chin $-0254 \times$ FMA angle $-0.16 \times$ the ratio of the lips. The critical score is equal to -5.92 in which case surgery is indicated.

Conclusion: This study focused on a clinical and cephalometric approach in the decision related to orthosurgical treatment, so as to choose better treatment options and limit the damaged caused by a more complex and costly options.

\section{KEY WORDS}

Orthognathic surgery, orthodontic camouflage, cephalometric criteria, clinical criteria, score

\section{INTRODUCTION}

In today's society, people are increasingly concerned about their appearance. This search for a better self-image is part of a need to be attractive that drives people and more specifically adults which encourages them to consult the dentofacial orthopedics service.
Therefore, the orthodontist must be able to meet these requirements while understanding the imperatives and peculiarities related to this treatment $4,9,17,18$.

Admittedly, orthodontic treatments significantly contribute to esthetic and functional improvements, but in some cases,

\section{Address for correspondence:}

Ines Dallel

Faculty of Dentistry - Avicenna Avenue

This is an Open Access article distributed under the terms of the Creative Commons Attribution License (http://creativecommons.org/licenses/by/4.0), which permits unrestricted use, distribution, and reproduction in any medium, provided the original work is properly cited. 
it can be limited with regard to major skeletal shifts 7,15 . Proper orthosurgical management with good multidisciplinary coordination will improve function with better stability of results. The consideration of the functional parameters involved in the treatment should be systematic ${ }^{10}$.

From a medical and legal point of view, the orthodontist must respect the patient's wishes after having informed them of the possible consequences of their choices ${ }^{3}$.

Several questions should be asked regarding the treatment decision: Can camouflage be a satisfactory solution? Will the result after surgery be more stable in the long term?

The purpose of this article is to investigate the parameters that determine our decision to establish orthosurgical treatment.

\section{PATIENTS AND METHODS}

This is a retrospective analytical study involving 175 healthy adult patients treated in the dentofacial orthopedics department at the Monastir Dental Clinic (Tunisia); these patients were randomly selected over a 4-year period.

With regard to surgical cases, surgery was performed at the maxillofacial surgery department of Sahloul Hospital (Sousse, Tunisia).

The material used for this study was based on the following: clinical and cephalometric parameters using the analysis of profile teleradiographies performed in occlusion with a 1:1
This is a real dilemma in our daily practice, the extent of which is often unknown, despite technological innovations in the field of therapeutic simulation using a range of new software ${ }^{1,14}$.

In this field and from the increase in the surgical demand to improve esthetics, we conducted a retrospective analytical study evaluating orthosurgical treatment needs in a sample of 175 patients who had consulted the orthopedics department of the Monastir Dental Clinic (Tunisia) over a 4-year period. These patients were randomly selected.

The objective of this study was to assess the need for orthosurgical treatment in patients seeking orthodontic treatment and to try to identify the main parameters involved in the decisions surrounding orthosurgical treatment.

scale; panoramic radiographs, extraoral and intraoral photographs; and information and clinical examination sheet developed for this study, which was previously tested and filled in using the clinical records of the study population (Figs. 1 and 2).

The sample included patients who were selected from a simple random draw according to the consultation registration list.

Several parameters were studied. In the information sheet, we analyzed all the elements related to the general condition, the clinical history, the 


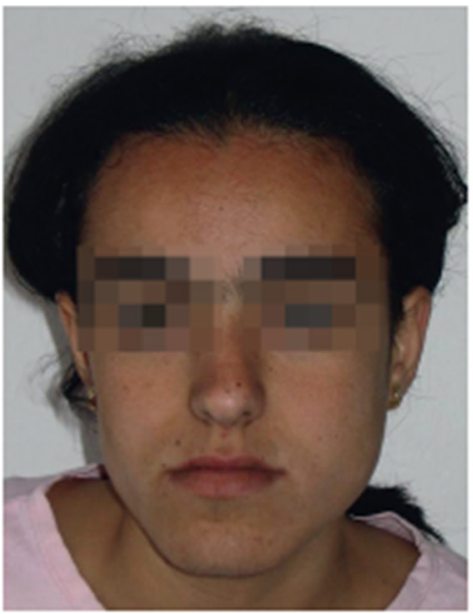

a

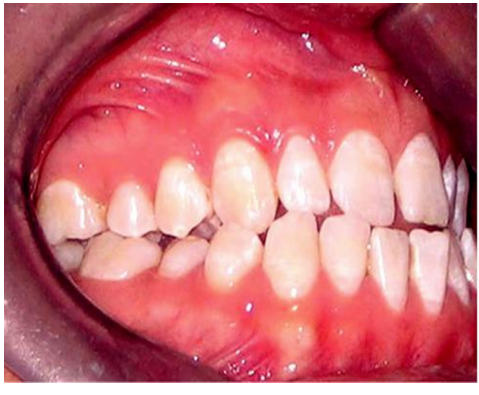

a

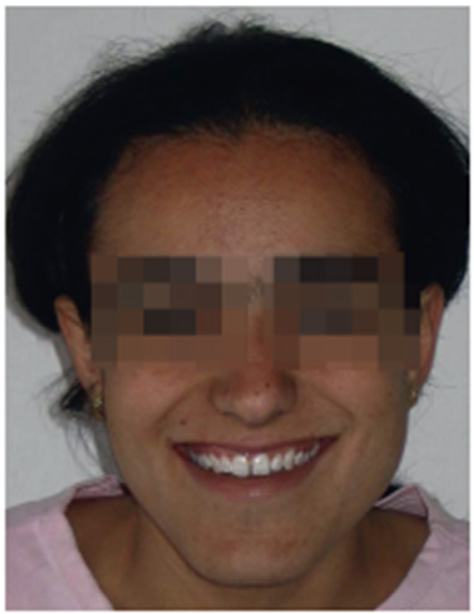

b

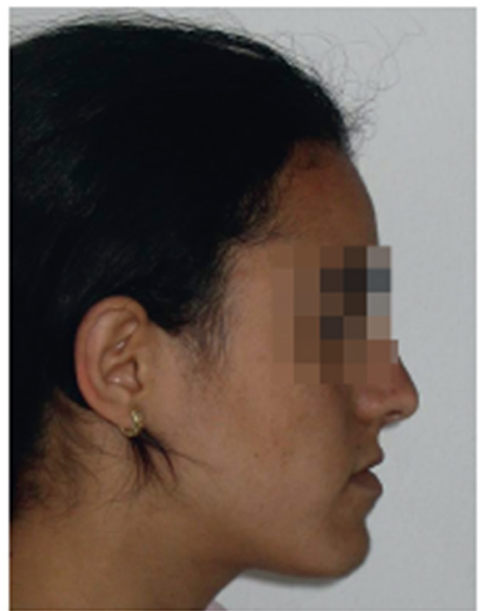

C

Figure 1

Extraoral photographs of a patient in the study. (a) Frontal view. (b) Photograph of the smile. (c) Profile view.

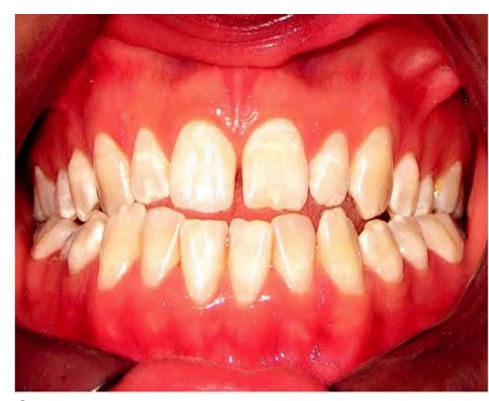

b

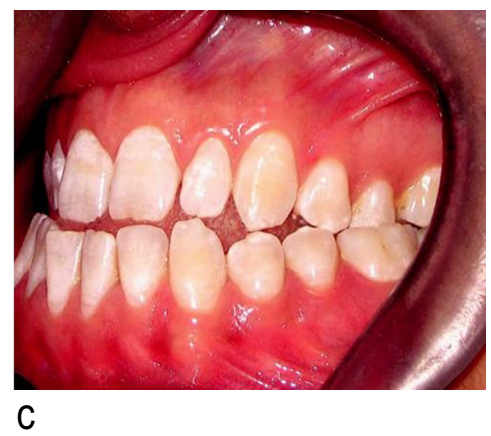

C

Figure 2

Intraoral photographs. (a) Right-side view. (b) The anterior occlusion. (c) Left-side view.

reason for consultation, the functional analysis, and the extraoral and intraoral examinations.

The types of sagittal, skeletal, dental and cutaneous dysmorphoses were determined by Tweed and Steiner's cephalometric analyses using the 1:1 scale profile teleradiographic images (Fig. 3). The type of profile is determined according to the guidelines set out by Simon and Dreyfus. In an ideal profile, the subnasal point is located on the vertical passing through the septum and the cutaneous pogonion is in the middle of the profile field.

Therefore, if the pogonion is in front of this median point, we classify our patient is classified as having prognathism; in the opposite case, retrognathism. 


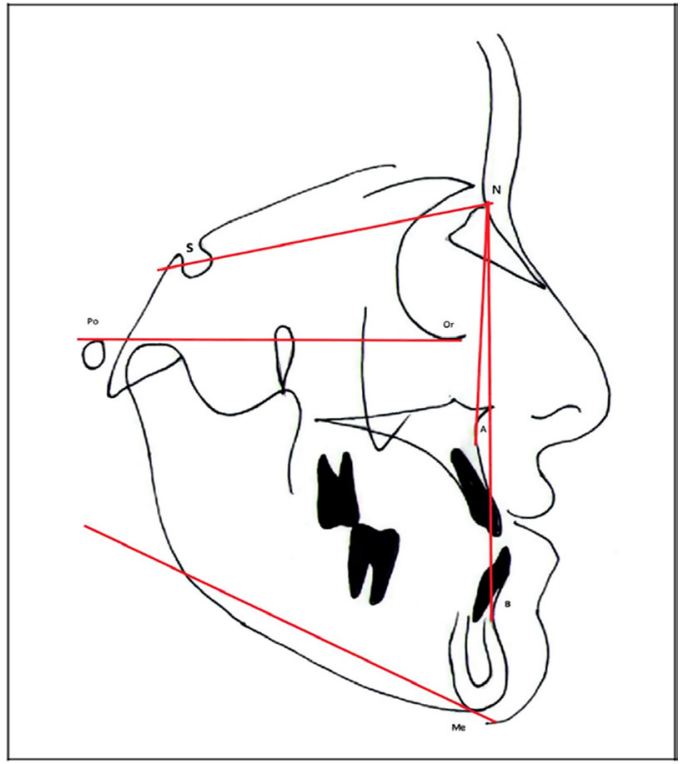

Figure 3

Cephalometric plot (same patient as in

Figure 1).

\section{RESULTS}

The study of the distribution of our population by gender (sex) showed that $69.1 \%(121)$ of women consulted the dentofacial orthopedics service of Monastir against $30.9 \%$ (54) of men; the female:male ratio was a $2: 1$, with an average age of 19 years and 4 months.

The reason for consultation for the majority of cases was esthetic, estimated at $89.1 \%$ (156 cases) against $8.6 \%$ (15 cases) in which the motive was functional; for $2.3 \%$ (4 cases), the reason was both esthetic and functional.

The study showed that $44 \%$ (77 cases) of patients had dysfunctions versus $56 \%$ (98 cases) who did not have functional disorders.
Regarding the therapeutic decision, we divided our sample into two subgroups; the first group, which required only orthodontic treatment, and the second group benefiting from orthosurgical treatment with or without profileplasty (genioplasty).

The data was collected by a single investigator to minimize the risk of measurement error.

Data analysis was performed using SPSS for Windows version 18.0 software.

For the analysis of qualitative variables, we used the chi-square statistical with a $p$ value of $<0.05$ considered significant.
Our sample was divided into three classes according to the Angle malocclusion classification, 55.4\% (97 cases) who had class-Il malocclusion versus $42.3 \%$ (74 cases) who had a class-I malocclusion; four cases had class-III malocclusion.

Several parameters were analyzed and divided into two distinct components, i.e., clinical parameters and cephalometric parameters measured using profile teleradiography. The calculation of the significance value was quantified using $p$ values. A $p$ value of $>0.05$ was considered not significant because it is a parameter that does not have a very high correlation of indication from the outset in orthognathic surgery. 


\section{Study of clinical parameters}

The study of the relationship between orthosurgical treatment and the cutaneous profile showed that there was no significant correlation $(p>0.05)$.

In fact, 18 patients, $13 \%$ of whose profile was convex, were prepared for orthognathic surgery; the rest of the patients were prepared for purely orthodontic treatment (Table 1).
Sex had no influence on surgical choice; $54.5 \%$ of orthosurgical cases were women and $45.5 \%$ were men were; this is because esthetics is no longer an issue only in women, and men are also concerned with their appearance.

The indication of bimaxillary surgery for $50.5 \%$ of orthosurgical cases (31.8\% bimaxillary associated with genioplasty and $18.7 \%$ bimaxillary without genioplasty).

Table 1: Clinical parameters influencing the therapeutic choice.

\begin{tabular}{|c|c|c|c|c|c|}
\hline & & $\begin{array}{l}\text { Orthosurgical } \\
\text { treatment N (\%) }\end{array}$ & $\begin{array}{l}\text { Purely orthodontic } \\
\text { treatment } \mathrm{N}(\%)\end{array}$ & $\begin{array}{c}\text { Total } \\
\text { N (100\%) }\end{array}$ & $p$ value \\
\hline \multirow{3}{*}{ Cutaneous profile } & Convex profile & $18(13 \%)$ & $120(87 \%)$ & 138 & \multirow{4}{*}{$\begin{array}{l}\text { N.S. } \\
\text { (not significant }\end{array}$} \\
\hline & Concave profile & $2(40 \%)$ & $3(60 \%)$ & 5 & \\
\hline & Right profile & $2(6.5 \%)$ & $30(93.5 \%)$ & 32 & \\
\hline Total & & $22(12.6 \%)$ & $153(87.4 \%)$ & 175 & \\
\hline \multirow{3}{*}{ Nasolabial angle } & Open & $9(18 \%)$ & $41(82 \%)$ & 50 & \multirow{4}{*}{ N.S. } \\
\hline & Closed & $6(7.2 \%)$ & $77(92.8 \%)$ & 83 & \\
\hline & Normal & $7(16.7 \%)$ & $35(83.3 \%)$ & 42 & \\
\hline Total & & $22(12.6 \%)$ & $153(87.4 \%)$ & 175 & \\
\hline \multirow{4}{*}{$\begin{array}{l}\text { Cervical chin } \\
\text { distance } \\
\text { (measured by } \\
\text { patient's fingers) }\end{array}$} & $\leq 2.5(\leq 5 \mathrm{~cm})$ & $2(16.7 \%)$ & $5(83.3 \%)$ & 7 & \multirow{5}{*}{ N.S. } \\
\hline & $3(\sim 6 \mathrm{~cm})$ & $11(13.8 \%)$ & $69(86.3 \%)$ & 80 & \\
\hline & $3.5(\sim 7 \mathrm{~cm})$ & $3(11.1 \%)$ & $24(88.9 \%)$ & 27 & \\
\hline & $4(\sim 8 \mathrm{~cm})$ & $6(9.8 \%)$ & $55(90.2 \%)$ & 61 & \\
\hline Total & & $22(12.6 \%)$ & $153(87.4 \%)$ & 175 & \\
\hline \multirow[t]{2}{*}{ Lip ratio } & Occlusion & $7(6.3 \%)$ & $105(93.8 \%)$ & 112 & \multirow{3}{*}{$p=0.002$} \\
\hline & Malocclusion & $15(23.8 \%)$ & $48(76.2 \%)$ & 63 & \\
\hline Total & & $22(12.6 \%)$ & $153(87.4 \%)$ & 175 & \\
\hline \multirow{3}{*}{ Gonial angle } & Open & $16(18.6 \%)$ & $70(81.4 \%)$ & 86 & \multirow{4}{*}{$p=0.04$} \\
\hline & Closed & $4(10 \%)$ & $36(90 \%)$ & 40 & \\
\hline & Normal & $2(4.1 \%)$ & $47(95.9 \%)$ & 49 & \\
\hline Total & & $22(12.6 \%)$ & $153(87.4 \%)$ & 175 & \\
\hline \multirow{3}{*}{$\begin{array}{l}\text { Position of the } \\
\text { chin (measured } \\
\text { in relation to } \\
\text { Simon's plan) }\end{array}$} & Prognathism & $5(26.3 \%)$ & 14 (73.7) & 19 & \multirow{4}{*}{$p=0.001$} \\
\hline & Retrognathism & $8(29.6 \%)$ & $19(70.4 \%)$ & 27 & \\
\hline & Normal & $9(7 \%)$ & $120(93 \%)$ & 129 & \\
\hline Total & & $22(12.6 \%)$ & 153 (87.4\%) & 175 & \\
\hline
\end{tabular}

Degree of significance: $p<0.05 ;$ NS: not significant. 


\section{Study of the cephalometric parameters}

The results of this study showed that there is a significant correlation between orthosurgical treatment and the A point-nasion-B point angle (ANB) angle $(p<0.05)$.

In fact, four out of 14 cases (28.6\%) with an ANB angle of $<0^{\circ}$ were candidates for orthognathic surgery.

Seventeen cases in class II, or $23.6 \%$, with an angle of $>4^{\circ}$, have benefited from orthosurgical treatment compared to $18.2 \%$ with a skeletal class III with a negative ANB angle (Table 2).

As shown in Table 2, there is a strong correlation between orthosurgical treatment and the FMA angle ( $P$ value <0.05).

In fact, two out of 30 clinical cases, or $6.7 \%$, with an Frankfort mandibular plane angle (FMA) angle of $<20^{\circ}$ (called hypodivergent cases), have been proposed as candidates for orthosurgical treatment against 12 cases with facial hyperdivergence.

\section{Multivariate analysis of the factors influencing the surgical indication}

This analysis consists of linking the main positive correlations between orthosurgical treatment and the rest of the variables in the study, based on their clinical, cephalometric, and statistical significance, which aims at eliminating any confusing variables and to keep only the variables that can be compared to the variables related to orthosurgical treatments.

Moreover, this analysis makes it possible to evaluate the contribution of each of the explanatory variables.

In this multivariate analysis, five variables presented highly significant correlations with orthosurgical treatment; three quantitative and two qualitative ones, which are as follows:

- ANB angle;

- SNB angle;

- FMA angle;

- lip ratio;

- chin position.

As shown in Table 3: three variables explain the need for orthosurgical treatment, namely, chin position, FMA angle, and the lip ratio. This means that the Sella-Nasion to B Point Angle (SNB) angle and especially the ANB angle are confounding variables.

From these correlations, we were able to determine the following formula according to which orthosurgical treatment can be proposed to patients:

Table 2: Correlation between orthosurgical treatment and cephalometric parameters.

\begin{tabular}{|c|c|c|c|c|c|}
\hline & & $\begin{array}{l}\text { Orthosurgical } \\
\text { treatment N (\%) }\end{array}$ & $\begin{array}{l}\text { Purely orthodontic } \\
\text { treatment } \mathrm{N}(\%)\end{array}$ & Total N (100\%) & $P$-value \\
\hline \multirow{3}{*}{ ANB angle } & $<0^{\circ}$ & $4(28.6 \%)$ & $10(71.4 \%)$ & $14(100 \%)$ & \multirow{4}{*}{$P=0.0001$} \\
\hline & {$\left[0^{\circ}, 4^{\circ}\right]$} & $1(1.1 \%)$ & $88(98.9 \%)$ & $89(100 \%)$ & \\
\hline & $>4^{\circ}$ & $17(23.6 \%)$ & $55(76.4 \%)$ & $72(100 \%)$ & \\
\hline Total & & $22(12.6 \%)$ & $153(87.4 \%)$ & $175(100 \%)$ & \\
\hline \multirow{3}{*}{ FMA angle } & $<20^{\circ}$ & $2(6.7 \%)$ & $28(93.3 \%)$ & $30(100 \%)$ & \multirow{3}{*}{$P=0.002$} \\
\hline & {$\left[20^{\circ}, 30^{\circ}\right]$} & $8(7.1 \%)$ & 105 (92.9\%) & $113(100 \%)$ & \\
\hline & $>30^{\circ}$ & $12(37.5 \%)$ & 20 (62.5\%) & 32 (100\%) & \\
\hline
\end{tabular}


A STUDY OF THE PARAMETERS THAT INFLUENCE ORTHOSURGICAL TREATMENTS

Table 3: Multivariate analysis of the parameters influencing the surgical indication.

\begin{tabular}{|c|c|c|c|c|c|}
\hline & Wald test & OR & IC 95\% & Beta & $P$ \\
\hline ANB angle & -1.162 & -0.010 & {$[-0.027,0.007]$} & -0.085 & 0.24 (NS) \\
\hline SNB angle & 1.758 & 0.011 & {$[-0.001,0.024]$} & 0.133 & 0.08 (NS) \\
\hline FMA angle & -3.425 & -0.014 & {$[-0.021,-0.006]$} & -0.254 & 0.001 (S) \\
\hline Lip ratio & -2.295 & -0.105 & {$[-0.195,-0.015]$} & -0.16 & 0.023 (S) \\
\hline Chin position & 4.342 & 0.142 & {$[0.078,0.207]$} & -0.288 & $<0.001$ (S) \\
\hline Constant & 1.167 & & & & \\
\hline
\end{tabular}

$N S=$ not significant, $S=$ significant, OR: odds ratio, Cl: confidence interval.

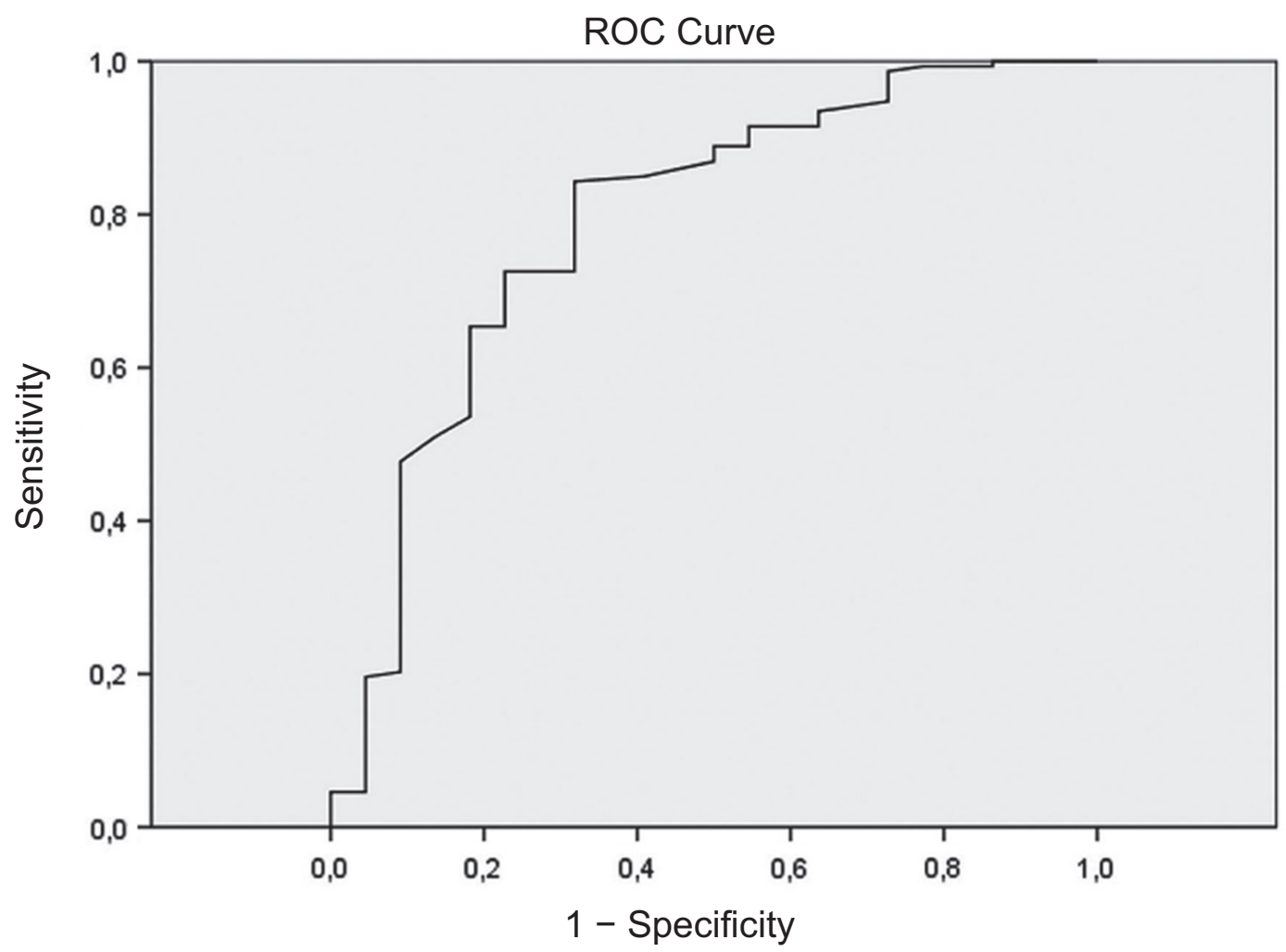

Diagonal segments are generated by links between the two axes

Figure 2

Intraoral photographs. (a) Right-side view. (b) The anterior occlusion. (c) Left-side view.

$y=1.167+0.288 \times$ chin position $0.254 \times$ FMA angle $-0.16 \times$ the lip ratio.

The critical score is -5.92 from which surgery is indicated with $84 \%$ statistically calculated sensitivity and $69 \%$ specificity (Figure 4).

Any patient with a score above the threshold score can be successfully treated orthodontically. 


\section{DISCUSSION AND RECOMMENDATIONS}

The results of the study of our sample showed that 153 cases $(87.4 \%)$ were judged correctable by orthodontic treatment against 22 cases that were judged treatable by orthognathic surgery.

We found that $90.9 \%$ of orthosurgical cases had an esthetic motive behind it, which confirms that the main objective of orthodontics is the resolution of an essentially esthetic problem.

For our present study, it should also be noted that orthosurgical treatment was significantly correlated with some variables in the study, with approximately 1:3 variables, including chin position, lip ratio, gonial angle, angle class, skeletal class, SNB value, FMA angle value, and ANB angle, showing correlations.

As part of the comparison of the multivariate analysis results, a German multicenter study of orthodontics from the University of Frankfurt, Heidelberg and Würzburg, which was conducted in 2002 by Angelika Stellzig-Eisenhauer, Christopher J. Lux, and Gabrielle Schuster $^{21}$. It involved 175 cases with skeletal class III, and the goal was to establish an equation separating orthosurgical cases from pure orthodontic cases.

In this context, they cephalometrically analyzed these patients by taking as study variables 20 linear and angular measurements. The results of the study showed that 87 cases, or $50 \%$ of the skeletal class-III cases were orthosurgical, versus $28.6 \%$ of the skeletal class-II cases requiring surgery. In this study, multivariate analysis showed that Wits appraisal, the length of the anterior cranial base SN (sella-nasion), maxillary/mandibular ratio, and gonial angle explained the orthosurgical treat- ment in skeletal class III, described using the following equation:

individual score $=-1.805+0.209 \times$ Wits $+0.044 \times \mathrm{SN}+5.689 \times \mathrm{M} / \mathrm{M}$ $-0.056 \times$ gonial angle.

Of all the variables, Wits appraisal was the most decisive variable in the choice of surgery for class III in most cases.

However, the absence of facial esthetic parameters analyzed in this study partially affects the validity of this discriminant analysis. Although our study was conducted on a population encompassing different types of skeletal reports (class I, class II, and class III), our multivariate analysis showed that the chin position, FMA value, and SNB angle are highly correlated and explain the choice of orthognathic surgery for a given clinical case; among these, chin position was the most decisive variable in orthosurgical treatment.

The equation was as follows:

$y=1.167+0.288 \times$ chin position $0.254 \times$ FMA angle $-0.16 \times$ lip ratio. The threshold score is equal to $\mathbf{- 5 . 9 2}$.

These explanatory variables of the orthosurgical treatment were different from the German study, and this can be explained, on the one hand, by the fact that our study was interested in all types of malocclusions, whereas most of the studies were concentrated only on Class III. Secondly, because of the difference between the ethnic characteristics of the two samples (North Africa and Western Europe) with variations between cephalometric 
standards ${ }^{11,20}$ and the esthetic criteria of the two countries (Tunisia and Germany $)^{21}$.

It should also be noted that we did not include some variables such as: Wits appraisal, the length of the base of the skull, and maxilla/mandible ratio in our study.

Another Moroccan study was conducted by Benyahia $\mathrm{H}^{2}$, which concerned class III treatment choices between orthognathic surgery and orthodontic camouflage. In fact, profile teleradiographies of 47 adult patients presented with skeletal class-III malocclusions.

This study has shown that a single variable makes it possible to distinguish between surgical and orthodontic cases.

This is Holdaway's $\mathrm{H}$ angle ${ }^{12,14}$ which has an individual score of $-1.498+$ (0.216 × Holdaway's $H$ angle). The threshold score is equal to 0.0575 , corresponding to a limit of the $\mathrm{H}$ angle, which is $7.2^{\circ}$.

Rabie $^{19}$ have also expressed interest in this angle for the indication of orthognathic surgery of class-III cases if its value is $<12^{\circ}$.

The limitation of these studies is that they focused only on patients with class III so other malocclusions were not considered. Moreover, it is difficult to judge the indications of orthognathic surgery from a single angle ${ }^{5}$.

Other more recent studies have shown an improvement in the quality of life after sagittal and vertical correction surgery, especially with the evolution of three-dimensional simulations which can be used to plan surgeries ${ }^{6,16,22}$ but some surgeries affecting the transversal dimension can have a negative impact ${ }^{8,13}$.

It would therefore be interesting to study this subject, which is multicentric and of potential interest for people in Mediterranean countries seeking orthodontic surgery, so as to create a more general formula whose sensitivity and specificity can be tested with the main objective: the separation of orthosurgical cases and purely orthodontic cases for all skeletal classes.

In addition, our study assessed the need for orthognathic surgery as a general objective, without monitoring longterm orthosurgical cases to ensure the stability of the results obtained, which may be the subject of further follow-up studies to find certain criteria such as the quality of the finished treatment and other factors that can favor or harm a sometimes quite expensive treatment.

\section{CONCLUSION}

The choice of appropriate therapy for each clinical situation, especially for borderline cases, is a challenge for the orthodontist.

Indeed, several parameters affect our decision such as patient motivation, their esthetic patterns, and occlusal and functional balance.
Our study has focused on a fairly important clinical approach to the decision of orthosurgical treatment; hence, we can expand the spectrum of this sample to include the entire population. This will make it possible to better visualize the treatment objectives, and more specifically to be 
able to generalize a clinical formula including a combination of certain parameters, which would confirm in an absolute way the choice of orthognathic surgery for a given clinical case.

Conflict of interest: The authors declare that they have no conflict of interest.

\section{REFERENCES}

1. Almukhtar A. Direct DICOM Slice Landmarking "A Novel Research Technique to Quantify Skeletal Changes in Orthognathic Surgery. PLoS One 2015;10:1-11.

2. Benyahia $\mathrm{H}$ et al. Treatment of skeletal class III malocclusions: orthognathic surgery or orthodontic camouflage? How to decide? Int Orthod 2011;9:196-209.

3. BERY A, Soyer Y. maxillofacial surgery and responsible-sabalites. Rev Orthop Dento Facial 2016;50:99-103.

4. Bousaba S, S Siciliano, Davis M, Faes J, Reychler H. Indications of the limits of Orthodontics and surgery, orthognatic surgery. Rev Belgian Med Dent 2002;57:9-23.

5. Burs NR et al. Class III camouflage treatment: what are the limits? Am J Orthod Dentofacial Orthop 2010;137:9-13.

6. Calignano F, Vezetti E. Soft tissue diagnosis in maxillofacial surgery: a preliminary study on three-dimensional face countdown features-based analysis. Aesthetic Plast Surg 2009; 34:200-11.

7. Cappellozza J. Orthodontic decompensation in skeletal Class III malocclusion: redefining the amount of motion assessed by Cone-Beam Computed Tomography. Dental Press J Orthod 2015;20:28-34.

8. Corso P. assessment of the impact of orthognathic surgery on quality of life. Braz Res Oral 2016;30:1-6.

9. Downs WB, Gugino C. Simplified cephalometric analysis. Encycl Med Chir (Elsevier-Paris), Odontology, Stomatology 23-455-D2000.

10. El Okeily M, Makaremi M blood Guy M, n M. ortho surgical strategy in 2016. Rev Orthop Dento Faciale 2016;50:189-206.

11. Foraster JB et al. Vertical facial dysplasia: diagnosis, treatment and therapeutic plan. Ortho en 2010;81:301-314.

12. Holdaway RA. Soft tissue cephalometric analysis. Am J Orthod 1983;84:1-28.

13. Huang $S$ et al. The changes of oral health-related quality of life and satisfaction after surgery-first orthognathic approach: a longitudinal prospective study. Head \& Face Medicine 2016;12:2-7.

14. Isiekwe Gl et al. Holdaway's analysis of the nose prominence of an adult Nigerian population. Nigerian Journal of Clinical Practice 2015; 18:548-552.

15. Lin HH. Comparative Validity and Reproducibility of Various Landmark-oriented References in 3-Dimensional Computed Tomographic Analysis for Patients Receiving Orthognathic Surgery. PLoS One 2015;10:1-16.

16. Lonic D, Lo LJ. Three-dimensional simulation of orthognathic surgery from the surgeon's perspective. J Med Assoc Trained. 2016;115(6):387-388. 
17. Mehrangiz $\mathrm{G}$ et al. Evaluation of soft and hard tissue changes after bimaxillary surgery in class III orthognathic surgery and aesthetic consideration. Nat J Maxillofac Surg 2014;5: 157-60.

18. Nachiappan S, Tharanikumar S. Study to evaluate hard tissue cephalometric profile of Tamil population for orthognathic surgery. J Pharm Sci 2015; 20 (5): 28-34 Bioallied.

19. Rabie et al. Treatment in borderline class III maloces: orthodontic camouflage (extraction) versus orthognatic surgery. Open Dent J 2008; 2:38-48.

20. Salo Fr et al. Prevalence and treatment of dento-facial deformities treatment has a multiethnic population: A retrospective study. Oral Maxillofacial Surgery 2014;18:173-179.

21. Stelllzig Eisenhauer A. Treatment decision in adult patients with orthodontic therapy or orthognathic surgery? Am J Orthod Dentofacial Orthop 2002;122:27-38.

22. Swennen GRJ, Mollemanns W, Schutyser F. Three-dimensional treatment planning of orthognathic surgery in the era of virtual imaging. J Oral Maxillofac Surg 2009;67: 2080-2092. 